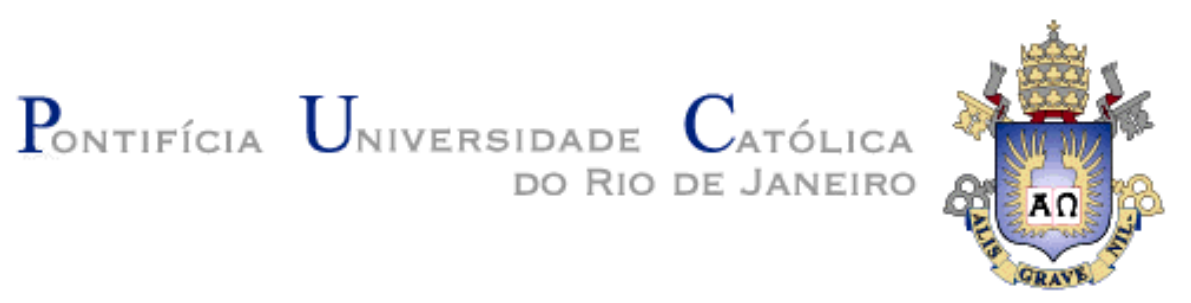

Jorge Luis Cárdenas Guillén

Modelagem Elasto-plástica da Liquefação Dinâmica de Solos

Tese de Doutorado

Tese apresentada como requisito parcial para obtenção do título de Doutor pelo Programa de Pós-Graduação em Engenharia Civil da PUC-Rio. Área de Concentração: Geotecnia.

Orientador: Celso Romanel

Rio de Janeiro

Dezembro de 2008 


$$
\text { Pontifícia Universidade } \text { Católica }_{\text {do Rio de Janeiro }}
$$

Jorge Luis Cárdenas Guillén

\title{
Modelagem Elasto-plástica da Liquefação Dinâmica de
}

Solos

\begin{abstract}
Tese apresentada como requisito parcial para obtenção do título de Doutor pelo Programa de Pós-Graduação em Engenharia Civil da PUC-Rio. Aprovada pela Comissão Examinadora abaixo assinada.
\end{abstract}

Prof. Celso Romanel

Presidente / Orientador

Departamento de Engenharia Civil - PUC-Rio

Prof. Raul Rosas e Silva

Departamento de Engenharia Civil - PUC-Rio

Prof. Paulo Batista Gonçalves

Departamento de Engenharia Civil - PUC-Rio

Prof. João Luis Pascal Roehl

Departamento de Engenharia Civil - PUC-Rio

Profa. Christianne de Lyra Nogueira

Universidade Federal de Ouro Preto

Prof. Francisco Cláudio Pereira de Barros

Comissão Nacional de Energia Nuclear - CNEN

Prof. José Eugênio Leal

Coordenador Setorial do Centro Técnico Científico - PUC-Rio

Rio de Janeiro, Dezembro de 2008 
Todos os direitos reservados. É proibida a reprodução total ou parcial do trabalho sem autorização da universidade, do autor e do orientador.

Jorge Luis Cárdenas Guillén

Graduou-se em Engenharia Civil pela Universidad Nacional de Ingeniería (UNI-Perú) em 1997. Atuou em engenharia geotécnica no Centro de Investigações Sísmicas e Mitigação de Desastres (CISMID-UNI). Em 2002 ingressou no curso de Mestrado e, em 2004, prosseguiu no curso de Doutorado em Engenharia Civil da Pontifícia Universidade Católica do Rio de Janeiro, na área de Geotecnia, onde vem desenvolvendo investigações na linha de pesquisa em Geomecânica Computacional.

Ficha Catalográfica

Cárdenas Guillén, Jorge Luis

Modelagem elasto-plástica da liquefação dinâmica de solos / Jorge Luis Cárdenas Guillén ; orientador: Celso Romanel. - 2008.

246 f. :il. ; $30 \mathrm{~cm}$

Tese (Doutorado em Engenharia Civil)-Pontifícia Universidade Católica do Rio de Janeiro, Rio de Janeiro, 2008.

Incluí bibliográfia

1. Engenharia civil - Teses. 2. Método dos elementos finitos. 3. Plasticidade generalizada. 4. Liquefação dinâmica. 5. Dinâmica de solos. I. Romanel, Celso. II. Pontifícia Universidade Católica do Rio de Janeiro. Departamento de Engenharia Civil. III. Título. 


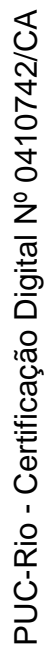

A minha mãe Maura. 


\section{Agradecimentos}

Não poderia começar estes agradecimentos sem expressar minha profunda e sincera gratidão ao Departamento de Engenharia Civil da PUC-Rio, pelos recursos fornecidos para a realização da presente tese, e a este grande Brasil, pela oportunidade de ter aqui vivido e conseguido realizar uma grande aspiração pessoal. Desejo também agradecer a todas as pessoas que contribuíram, de uma ou outra maneira, com o desenvolvimento deste trabalho, em particular a:

ao professor e orientador Celso Romanel, pela orientação e amizade. Os seus ensinamentos, sugestões e correção do manuscrito final tornaram possível a apresentação da tese na presente forma;

a meus pais Maura e Maximo (Don Max), pelo inmenso amor recibido;

a minhas irmãs Alicia Cristina (negra Lí), Corina (Vicky) e Blanca Pilar (Pili), pelo apoio em todo momento;

a meu irmaaozinho Luis Angel (in memoriam), pela luz eterna;

a Hilda, pelo amor e apoio continuo durante a tese;

ao professor e colega de trabalho Mitsuo Tsutsumi, da Universidade Federal de Juiz de Fora, pela amizade, confiança e respeito;

a David Luna, do Laboratório de Geotecnia da Universidad Nacional de Ingeniería no Perú, pelo apoio e amizade;

a Mery Cecilia, Flavio Silva, Marcos Ramidan, Fanny e Sandra Milagros, pela confiança e apoio recebido; 
a meus colegas da PUC-Rio, pela amizade, convivência e apoio nestes anos de estudo;

a Rita, pela auxílio em todos os momentos de necessidade;

aos professores do Departamento de Engenharia Civil da PUC-Rio, pelos excelentes conhecimentos transmitidos durante o curso de Doutorado;

a CNPq pelo apoio financeiro;

muito obrigado a todos. 


\section{Resumo}

Guillén, Jorge Cárdenas; Romanel, Celso. Modelagem elasto-plástica da liquefação dinâmica de solos. Rio de Janeiro, 2008. 246p. Tese de Doutorado - Departamento de Engenharia Civil, Pontifícia Universidade Católica do Rio de Janeiro.

Mudanças das propriedades dos solos devido à ação de carregamentos dinâmicos são responsáveis por danos significativos em geo-estruturas, tais como: barragens, estruturas de contenção, fundações, taludes, etc. A ocorrência do fenômeno da liquefação, em materiais suscetíveis como areias fofas saturadas, representa um tipo de resposta desastrosa de solos. O termo liquefação tem sido empregado para descrever uma variedade de fenômenos no qual tem em comum o desenvolvimento de altas poropressões em materiais saturados sem coesão devido a carregamentos monotônicos, transientes ou cíclicos. A previsão da liquefação depende de uma adequada análise do comportamento não-drenado do material, em termos do incremento de poropressões e da perda da rigidez da mistura sólidofluido, durante e após o período de movimento. O estabelecimento das equações governantes é essencial para elaboração de um modelo matemático realista para descrever o comportamento físico deste fenômeno. As equações a serem consideradas são: equação de movimento da fase sólida, a equação do movimento da mistura sólido-fluido, a equação de continuidade da fase fluida, as equações de acoplamento das fases e as equações constitutivas desses materiais. Nesta tese a resposta dinâmica do solo foi investigada numericamente mediante a técnica dos elementos finitos. A discretização espacial das equações governantes foi feita através do método de Galerkin e a discretização temporal pelo método de Newmark Generalizado. Um modelo constitutivo elasto-plástico foi considerado para descrever o comportamento mecânico da fase sólida, desenvolvido a partir de conceitos da generalização da teoria da plasticidade, que apresenta algumas vantagens em relação aos outros modelos baseados na teoria da plasticidade clássica. A implementação computacional foi escrito em Fortran 90. Exemplos numéricos analisados nesta tese comprovam tanto a eficiência do modelo constitutivo na predição do comportamento do solo sobre liquefação como a confiabilidade do programa computacional elaborado nesta pesquisa, em termos 
da rapidez de processamento e da boa precisão dos resultados, quando comparados com soluções analíticas e outros valores numéricos obtidos por vários autores e diferentes modelos constitutivos.

\section{Palavras-chave}

Método dos elementos finitos, plasticidade generalizada, liquefação dinâmica, dinâmica de solos. 


\section{Abstract}

Guillén, Jorge Cárdenas; Romanel, Celso (Advisor). Elasto-Plasticity Modelling of Soil Liquefaction. Rio de Janeiro, 2008. 246p . DSc. Thesis

- Departamento de Engenharia Civil, Pontifícia Universidade Católica do Rio de Janeiro.

Changes in soil properties due to the action of dynamic loads are responsible for significant damage of geo-structures such as dams, retaining structures, building foundations, slopes, etc. The occurrence of liquefaction phenomena in susceptible materials, such as loose sand saturated, represents a type of disastrous response of soil. The term liquefaction has been used to refer to a group of phenomena which have in common the development of high pore pressures in saturated cohesionless material due to monotonic, transient, or cyclic loads. The prediction of soil liquefaction depends of an adequate analysis of the behavior of undrained materials, in terms of increase of pore water pressure and weakening of the solid-fluid mixture, during and after the periodic motion. The establishment of the governing equations is essential to provide a realistic mathematical model to describe the physical behavior of this phenomenon. The system of equations to be considered are: the equilibrium equation of the solid phase, the equilibrium equation of the solid-fluid mixture, the conservation mass of the fluid phase, the coupling equation of phases, and the constitutive equations of materials. In this thesis the soil dynamic response was numerically investigated by the finite element method. To obtain the spatial discretization of the governing equation, the Galerkin method was used. The dicretization in time was the Generalized Newmark method. An elastic-plastic constitutive model was used to describe the mechanical behavior of the solid phase. This model was developed in the framework of the generalized theory of plasticity, which has some advantages when compared with other models based on the classical plasticity theory. The computational implementation was written in Fortran 90. Numerical examples considered in this thesis demonstrate the efficiency of the constitutive model to simulated the predicted behavior of soil under liquefaction as well as the reliability of the software developed in this research, in terms of computational effort and good accuracy of the results, when 
compared with some analytical solutions and other numerical values obtained by various authors and different constitutive models.

\section{Keywords}

Finite element method, generalized plasticity, dynamic liquefaction, soil dynamic. 


\section{Sumário}

1 Introdução $\quad 38$

$\begin{array}{ll}1.1 \text { Aspectos gerais } & 38\end{array}$

1.2 Motivação e objetivo 44

1.3 Organização da tese 46

$\begin{array}{ll}1.4 \text { Notação utilizada } & 47\end{array}$

2 Fundamentos teóricos da liquefação de solos 48

2.1 Aspectos gerais $\quad 48$

2.2 Fenômeno da liquefação de solos $\quad 49$

2.2.1 Definição 49

2.2.2 Fluxo por liquefação e mobilidade cíclica 49

2.3 Comportamento dinâmico não-drenado de areias saturadas 53

2.4 Mecanismo de iniciação da liquefação 62

2.5 Suscetibilidade dos materiais à liquefação 66

2.5.1 Critério geológico 66

2.5.2 Critério de composição de material 66

2.5.3 Critérios de estado $\quad 69$

3 Modelo constitutivo para liquefação de solos $\quad 76$

$\begin{array}{ll}3.1 \text { Aspectos gerais } & 76\end{array}$

3.2 Desenvolvimento histórico dos modelos constitutivos para $\begin{array}{ll}\text { carregamento cíclico } & 78\end{array}$

3.3 Teoria da plasticidade generalizada 86

3.3.1 Principais características da teoria da plasticidade clássica $\quad 87$

3.3.2 Características da teoria da plasticidade generalizada 90

3.3.3 Formulação da matriz constitutiva elasto-plástica 96

$\begin{array}{ll}\text { 3.4 Modelo constitutivo Pastor-Zienkiewicz } & 97\end{array}$

3.4.1 Formulação geral do modelo no plano triaxial 97

3.4.2 Sumário da formulação do modelo no plano triaxial 109

3.4.3 Formulação do modelo no espaço das tensões principais 113 
4 Equações governantes da interação dinâmica sólido-fluido

4.1 Introdução

$\begin{array}{ll}\text { 4.2 Aspectos gerais } & 117\end{array}$

4.2.1 Lei de Darcy 121

4.2.2 Principio das tensões efetivas de Terzaghi 122

$\begin{array}{ll}4.3 \text { Equações governantes } & 124\end{array}$

4.3.1 Forma incremental das equações completas de Biot-Zienkiewicz 126

4.3.2 Forma incremental das equações simplificadas de

$\begin{array}{ll}\text { Biot-Zienkiewicz } & 128\end{array}$

5 Discretização das equações governantes na forma u-p 131

5.1 Discretização espacial 131

$\begin{array}{ll}5.2 \text { Discretização temporal } & 147\end{array}$

5.3 Linearização das equações discretas dos sistema sólido-fluido 152

6 Exemplos $\quad 157$

6.1 Características gerais do programa computacional 157

6.2 Retroanálises de ensaios de laboratório em areias 158

6.2.1 Parâmetros do modelo Pastor-Zienkiewicz 158

6.2.2 Retroanálises de ensaios triaxiais monotônicos em areias 160

6.2.3 Retroanálises de ensaios de cisalhamento cíclico em areias 167

6.3 Exemplo 1 - coluna de solo submetida à excitação cíclica na base 170

6.3.1 Solo seco 170

$\begin{array}{ll}\text { 6.3.2 Solo saturado } & 173\end{array}$

6.4 Exemplo 2 - Análise dinâmica da barragem de San Fernando, EUA 181

6.5 Exemplo 3 - Resposta dinâmica de um talude de solo submerso 186

7 Conclusões e sugestões 194

$\begin{array}{ll}7.1 \text { Conclusões } & 194\end{array}$

$\begin{array}{ll}7.2 \text { Sugestões para futuras pesquisas } & 197\end{array}$

8 Referências bibliográficas 198

$\begin{array}{ll}\text { Anexo A } & 221\end{array}$

$\begin{array}{ll}\text { Anexo B } & 225\end{array}$

Anexo C 232

$\begin{array}{ll}\text { Apêndices } & 237\end{array}$ 


\section{Lista de figuras}

Figura 1.1 - Liquefação do solo de fundação em Niigata, Japão, 1964, causando colapso do conjunto habitacional Kawagishi-cho [Earthquake Engineering Research Center, University of California, Berkeley, USA].

Figura 1.2 - Liquefação do solo no terremoto de Good Friday, Alaska, 1964, causando grandes movimentos de massas [Earthquake Engineering Research Center, University of California, Berkeley, USA].

Figura 2.1 - Ensaios triaxiais não-drenados em amostra de areia saturada [Castro, G.; Poulos, S.J., 1977].

Figura 2.2 - Amostra M1 com $D_{r}=0,44$ e $C S R=0,08$. Resultados do ensaio de cisalhamento cíclico não-drenado da areia do Rio Fraser. (a)

Curva $\sigma_{v}^{\prime}: \tau$. (b) Curva $N_{C}: \delta p_{w} / \sigma_{v 0}^{\prime}$, [Byrne, P.M., 2005].

Figura 2.3 - Amostra M2 com $D_{r}=0,80$ e $C S R=0,25$. Resultados do ensaio de cisalhamento cíclico não-drenado da areia do Rio Fraser. (a) Curva $\sigma_{v}^{\prime}: \tau$. (b) Curva $N_{C}: \delta p_{w} / \sigma_{v 0}^{\prime}$, [Byrne, P.M., 2005].

Figura 2.4 - Amostra M3 com $D_{r}=0,44$ e $C S R=0,10$. Resultados de ensaio de cisalhamento cíclico não-drenado da areia do rio Fraser. (a) Curva $\sigma_{v}^{\prime}: \tau$. (b) Curva $N_{C}: \delta p_{w} / \sigma_{v 0}^{\prime}$, [Byrne, P.M., 2005].

Figura 2.5 - Trajetória das tensões típica num ensaio cisalhante cíclico.

Plano $\sigma_{v}^{\prime}: \tau$.

Figura 2.6 - Linha de transformação de fase (PLT) e linha de estado permanente (SSL) nas amostras M2 (a) e M3 (b).

Figura 2.7 - Esquema geral da resposta não-drenada de areias saturadas sob carregamento monotônico e cíclico. (a) Comportamento contrativo. (b) Comportamento dilatante, [Rauch, A.F., 1997].

Figura 2.8 - Conceito de iniciação da ruptura do fluxo por liquefação, [Kramer, S.L., 1996].

Figura 2.9 - Superfície de iniciação de ruptura do fluxo por liquefação.

Plano $p^{\prime}: q$, [Kramer, S.L., 1996].

Figura 2.10 - Região de suscetibilidade de ocorrência de fluxo por liquefação, [Kramer, S.L., 1996].

Figura 2.11 - Região de suscetibilidade de ocorrência de mobilidade 
cíclica, [Kramer, S.L., 1996].

Figura 2.12 - Recomendações de Seed, R.B. [Seed, R.B., et al., 2003] considerando a influência dos finos na suscetibilidade da liquefação. $\quad 68$

Figura 2.13 - Linha de índice de vazio crítico, [Kramer, S.L., 1996]. 70

Figura 2.14 - Comportamento típico de areias em ensaios triaxiais nãodrenados monotônicos. (a) Plano: $\varepsilon_{a}: q$, (b) Plano: $p^{\prime}: q$, (c) Plano: $\varepsilon_{a}: p_{w},[$ Kramer, S.L., 1996].

Figura 2.15 - Linha de estado permanente em representação

tridimensional no espaço $e: \tau: \sigma^{\prime}$ e nos planos $\tau: e, \tau: \sigma^{\prime}$, e $e: \sigma^{\prime}$, [Kramer, S.L., 1996].

Figura 2.16 - Proporcionalidade entre a linha de estado permanente baseada em (a) resistência não-drenada e (b) tensão de confinamento efetiva (escala logarítmica), [Kramer, S.L., 1996].

Figura 2.17 - Estimativa da suscetibilidade de liquefação pela linha de estado permanente, [Kramer, S.L., 1996].

Figura 2.18 - Definição do parâmetro de estado $\psi$ [Been, K.; Jefferies,

M.G., 1985].

Figura 3.1 - Deslizamento ocorrido na barragem de San Fernando, em 1971 (EERC, University of California, Berkeley, USA).

Figura 3.2 - Ruptura da barragem San Fernando. (a) Seção transversal da barragem após a ruptura e (b) reconstrução das condições iniciais, [Seed, H.B., 1979].

Figura 3.3 - Representação de um ciclo de carregamento num ensaio triaxial cíclico uniaxial.

Figura 3.4 - Influência de $\hat{p}_{g_{0}}^{\prime}$ na forma da superfície do potencial

plástico $\left(\alpha=0,6, M_{g}=1,6\right)$.

Figura 3.5 - Influência de $M_{g}$ na forma da superfície do potencial plástico $\left(\alpha=0,6, \hat{p}_{g_{0}}^{\prime}=200 \mathrm{kPa}\right)$.

Figura 3.6 - Influência de $\alpha$ na forma da superfície do potencial plástico $\left(M_{g}=1,6, \hat{p}_{g_{0}}^{\prime}=200 \mathrm{kPa}\right)$.

Figura 4.1 - Representação esquemática de um meio poroso preenchido com um ou dois fluidos, [Bastian, P., 1999].

Figura 4.2 - Representação esquemática de um meio poroso permeável e impermeável. 
Figura 4.3 - Fases do solo; (a) estado natural, (b) representação esquemática em termos de volumes e massas.

Figura 6.1 - Previsão da curva tensão efetiva média-tensão de desvio nos ensaios triaxiais monotônicos em areias [Castro, G., 1969] com emprego do modelo P-Z.

Figura 6.2 - Previsão da curva deformação cisalhante-tensão de desvio nos ensaios triaxiais monotônicos em areias [Castro, G., 1969] com emprego do modelo P-Z.

Figura 6.3 - Previsão da curva deformação cisalhante-poropressão nos ensaios triaxiais monotônicos em areias [Castro, G., 1969] com emprego do modelo P-Z.

Figura 6.4 - Influência do parâmetro $\alpha$ na representação da trajetória de tensão efetiva $p^{\prime}: q$ nos ensaios monotônicos com emprego do modelo P-Z.

Figura 6.5 - Influência do parâmetro $\beta_{0}$ na representação da trajetória de tensão efetiva $p^{\prime}: q$ no ensaio monotônico com emprego do modelo P-Z.

Figura 6.6 - Influência do parâmetro $\beta_{1}$ na representação da trajetória de tensão efetiva $p^{\prime}: q$ nos ensaios monotônicos com emprego do modelo P-Z.

Figura 6.7 - Influência do parâmetro $H_{L_{0}}$ na representação da trajetória de tensão efetiva $p^{\prime}: q$ nos ensaios monotônicos com emprego do modelo P-Z.

Figura 6.8 - Influência exponencial $(n=0 ; 1 ; 2 ; 3 ; 4 ; 5)$ da razão da tensão efetiva média com a tensão de confinamento efetiva na representação da trajetória de tensão efetiva $p^{\prime}: q$ nos ensaios monotônicos com emprego do modelo P-Z modificado.

Figura 6.9 - Previsão da curva tensão efetiva média - tensão de desvio nos ensaios triaxiais monotônicos em areias [Ishihara, K., 1993] com emprego do modelo P-Z.

Figura 6.10 - Previsão da curva tensão efetiva média - tensão de desvio nos ensaios triaxiais monotônicos em areias [Ishihara, K., 1993] com emprego do modelo P-Z modificado.

Figura 6.11 - Previsão da trajetória de tensões efetivas para distintos 
valores de tensões de confinamento $\left(\sigma_{3}^{\prime}=0,5 ; 1,5 ; 2,5 ; 3,5 \mathrm{MPa}\right)$ nos ensaios triaxiais monotônicos em areias [Ishihara, K., 1993] com emprego do modelo P-Z modificado.

Figura 6.12 - Previsão da curva tensão efetiva média - tensão de desvio nos ensaios triaxiais cíclicos de areias com emprego do modelo P-Z.

Figura 6.13 - Previsão da curva deformação cisalhante - tensão de desvio nos ensaios triaxiais cíclicos de areias com emprego do modelo P-Z.

Figura 6.14 - Previsão da curva deformação cisalhante - poropressão nos ensaios triaxiais cíclicos de areias com emprego do modelo P-Z.

Figura 6.15 - (a) Coluna de solo seco submetida a carregamento sísmico em sua base; (b) Malha de elementos finitos Q4 utilizada na análise numérica.

Figura 6.16 - Comparação entre respostas numérica e analítica para deslocamentos do ponto $B$.

Figura 6.17 - Comparação entre respostas numérica e analítica para deslocamentos do ponto $A$.

Figura 6.18 - (a) Coluna de solo, com presença do lençol freático, submetida a carregamento (aceleração) sísmico em sua base; (b) Malha de elementos finitos Q4 utilizada na análise numérica.

Figura 6.19 - Variação do incremento de poropressão com a profundidade e tempo para $a_{0}=0.35 \vec{g}$.

Figura 6.20 - Variação do incremento de poropressão com a profundidade e tempo para $a_{0}=0.40 \vec{g}$.

Figura 6.21 - Variação do incremento da poropressão com o tempo para vários valores da amplitude da aceleração aplicada na base.

Figura 6.22 - Curva da variação da tensão de confinamento efetiva com a profundidade no tempo $\mathrm{t}=10 \mathrm{~s}$ para $a_{0}=0,35 \vec{g}$ e $0,40 \vec{g}$.

Figura 6.23 - (a) Trajetória de tensão no plano triaxial para $a=0,40 \vec{g}, \mathrm{t}$ $=10 \mathrm{~s}, \mathrm{z}=20 \mathrm{~m}$, (b) Curvas tensão-deformação durante carregamento cíclico.

Figura 6.24 - Variação com a profundidade do fator de segurança contra a liquefação FS.

Figura 6.25 - Registro das acelerações sísmicas utilizado na simulação numérica. 
Figura 6.26 - Geometria e malha de elementos finitos. Barragem de San Fernando. Letras C, D, G e H se referem a pontos nodais de interesse.

Figura 6.27 - Variação temporal do incremento de poropressões determinados numericamente para alguns pontos da barragem de San Fernando.

Figura 6.28 - Geometria do problema e localização dos pontos de instrumentação. Talude de solo submerso [Byrne, P.M., 2005].

Figura 6.29 - Registro das acelerações instrumentadas. Pontos A2, A5 e A7.

Figura 6.30 - Registros das poropressões instrumentadas. Pontos P2, P5 e P7.

Figura 6.31 - Registro das acelerações do sismo A475 [Byrne, P.M., 2005].

Figura 6.32 - Geometria e malhas de elementos finitos. Talude de solo submerso.

Figura 6.33 - Registro das acelerações previstas. Ponto A2.

Figura 6.34 - Registro das acelerações previstas. Ponto A5.

Figura 6.35 - Registro das acelerações previstas. Ponto A7.

Figura 6.36 - História das poropressões previstas. Ponto P2.

Figura 6.37 - História das poropressões previstas. Ponto P5. 


\section{Lista de tabelas}

Tabela 6.1 - Parâmetros do modelo P-Z utilizados nas retroanálises dos ensaios de laboratório monotônicos em areias [Castro, G., 1969].

Tabela 6.2 - Parâmetros do modelo P-Z utilizados nas retroanálises dos ensaios de laboratório monotônicos em areias [Ishihara, K., 1993].

Tabela 6.3 - Parâmetros utilizados para obtenção do módulo de cisalhamento e do modulo volumétrico dependentes da tensão de cisalhamento.

Tabela 6.4 - Parâmetros do modelo P-Z utilizados nas retroanálises dos ensaios de laboratório cíclicos em areias [Byrne, P.M., 2005].

Tabela 6.5 - Parâmetros do material, da aceleração sísmica e da geometria da coluna de solo seco.

Tabela 6.6 - Comparação dos deslocamentos numéricos máximos com a solução analítica.

Tabela 6.7 - Parâmetros do material da coluna de solo saturado.

Tabela 6.8 - Parâmetros do modelo P-Z da coluna de solo saturado.

Tabela 6.9 - Parâmetros utilizados para obtenção do módulo de cisalhamento dependente da tensão de confinamento efetiva.

Tabela 6.10 - Cálculo do fator de segurança contra a liquefação para

$$
M_{W}=6 \frac{3}{4} \text {. }
$$

Tabela 6.11 - Cálculo do fator de segurança contra a liquefação para

$$
M_{W}=7 \frac{1}{2}
$$

Tabela 6.12 - Cálculo do fator de segurança contra a liquefação para

$$
M_{W}=8 \frac{1}{2}
$$

Tabela 6.13 - Parâmetros dos materiais da barragem de San Fernando

Tabela 6.14 - Parâmetros do modelo P-Z para os materiais da

barragem de San Fernando.

Tabela 6.15 - Propriedades do material do talude (areia fofa). 


\section{Lista de Abreviaturas}

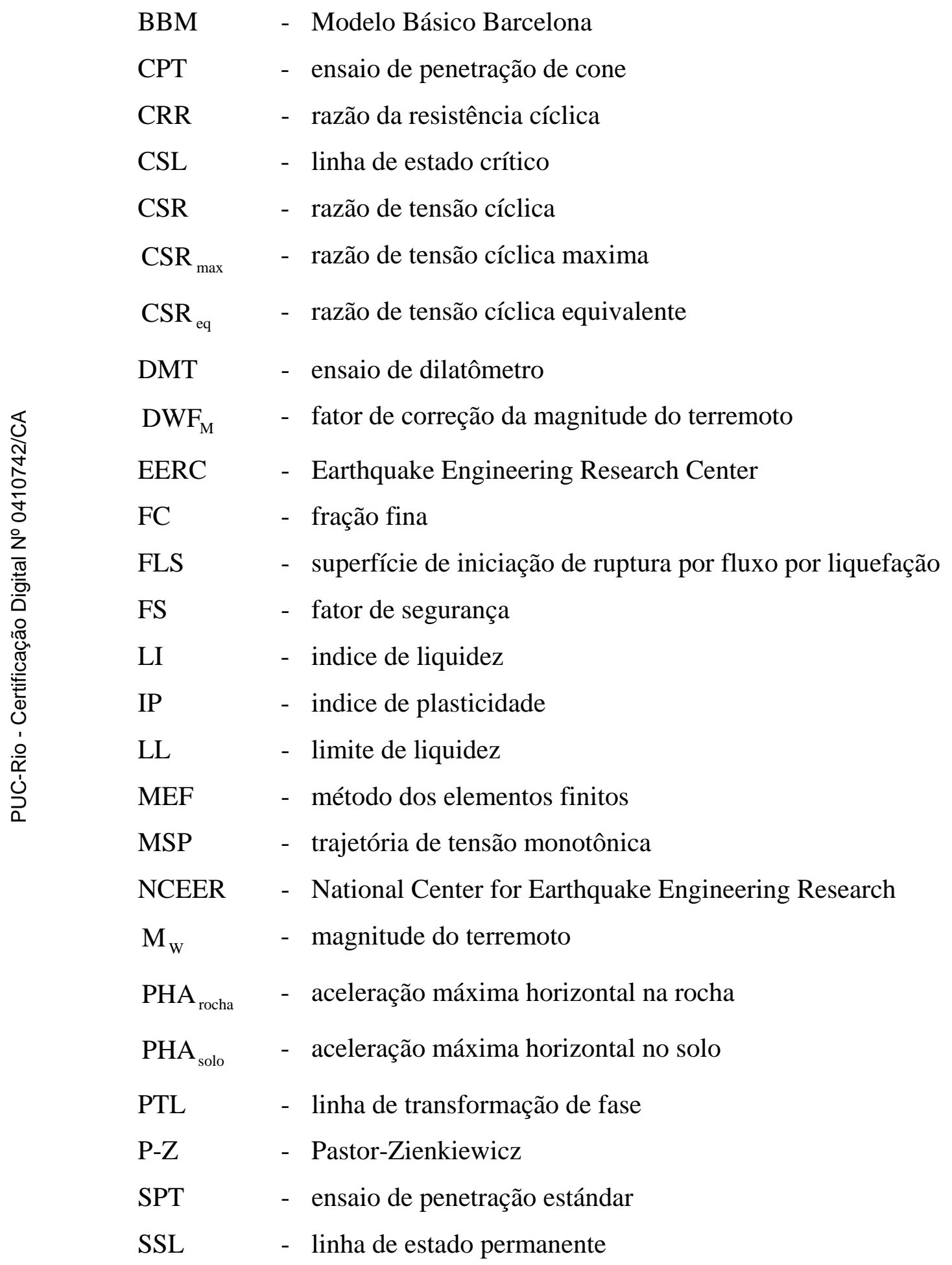




\section{Lista de símbolos}

\section{ALFABETO ROMANO}

$a$

- aceleração horizontal

$a_{\max }$

- aceleração horizontal máxima

$a_{0}$

- amplitude da aceleração

$a_{1}, a_{2}$

- constantes de amortecimento

A

- área da seção transversal

$A_{0}$

- amplitude do deslocamento

$\mathbf{A}_{1}, \mathbf{A}_{2}, \mathbf{A}_{3}$

- quantidades matriciais

$b_{i}$

- componente do vetor $\mathbf{b}$

b

- vetor de força de corpo por unidade de massa

$\overrightarrow{\mathbf{b}}$

- vetor unitário de força de corpo

$\mathbf{B}^{w}$

- matriz das derivadas das funções de interpolação do fluido

$\mathbf{B}^{u}$

- matriz das derivadas das funções de interpolação do sólido

$\mathbf{B}_{1}, \mathbf{B}_{2}, \mathbf{B}_{3}$

- quantidades matriciais

$C_{i j k l}$

- tensor constitutivo deformação-tensão

$C_{i j k l_{L}}$

- tensor constitutivo deformação-tensão (carrregamento)

$C_{i j k l}{ }_{U}$

- tensor constitutivo deformação-tensão (descarregamento)

$C_{s}$

- compressibilidade do sólido

$C_{w}$

- compressibilidade da água

$C_{N}$

- fator de correção

$C_{T}$

- compressibilidade do sistema sólido-água

$\tilde{C}$

- compressibilidade equivalente do sistema sólido-água 
- compressibilidade equivalente do sistema sólido-água-ar

$[C]$

- matriz de amortecimento viscoso do sólido a nível local

C

- matriz constitutiva deformação-tensão

C

- matriz de amortecimento viscoso do sólido a nível local

$\mathbf{C}^{e}$

- matriz constitutiva deformação-tensão elástica

$\mathbf{C}_{c}$ matriz de acoplamento sólido-fluido em termos da rigidez a nível local

$\mathbf{C}_{L}$

- matriz constitutiva deformação-tensão (carregamento)

$\mathrm{C}_{R} \quad$ - matriz de amortecimento de Rayleigh

$\mathbf{C}_{U}$

- matriz constitutiva deformação-tensão (descarregamento)

$\overline{\mathbf{C}}_{e}$

- matriz de amortecimento do elemento acoplado

$\tilde{\mathbf{C}}$

- matriz de amortecimento do sólido a nível global

$\tilde{\mathbf{C}}_{s}$

- matriz de amortecimento do sistema

$d$

$d_{f}$

$d_{g}$

$D_{i j k l}$

$D_{r}$

$\hat{D}_{q}^{e}$

$\hat{D}_{p}^{e}$

$\hat{D}_{i j}^{e p}$

D

$\mathbf{D}^{e}$

$\mathbf{D}^{e p}$

$\mathbf{D}_{f}$

$\mathbf{D}_{s}$

$\hat{\mathbf{D}}^{e}$

$\hat{\mathbf{D}}^{e p}$

- dilatância plástica

dilatância plástica dependente da superfície de escoamento modelo P-Z

dilatância plástica dependente da superfície do potencial plástico - modelo P-Z

- tensor constitutivo tensão-deformação

- densidade relativa

- componente de desvio da matriz $\hat{\mathbf{D}}^{e}$

- componente volumétrica da matriz $\hat{\mathbf{D}}^{e}$

- componente da matriz $\hat{\mathbf{D}}^{e p}(i, j=1,2)$

- matriz constitutiva tensão-deformação

- matriz constitutiva tensão-deformação elástica

- matriz constitutiva tensão-deformação elasto-plástica

- matriz de amortecimento viscoso do fluido a nível local

- matriz de amortecimento viscoso do sólido a nível local

matriz constitutiva tensão-deformação elástica - plano triaxial $p^{\prime}: q$

- matriz constitutiva tensão-deformação elasto-plástica - plano 


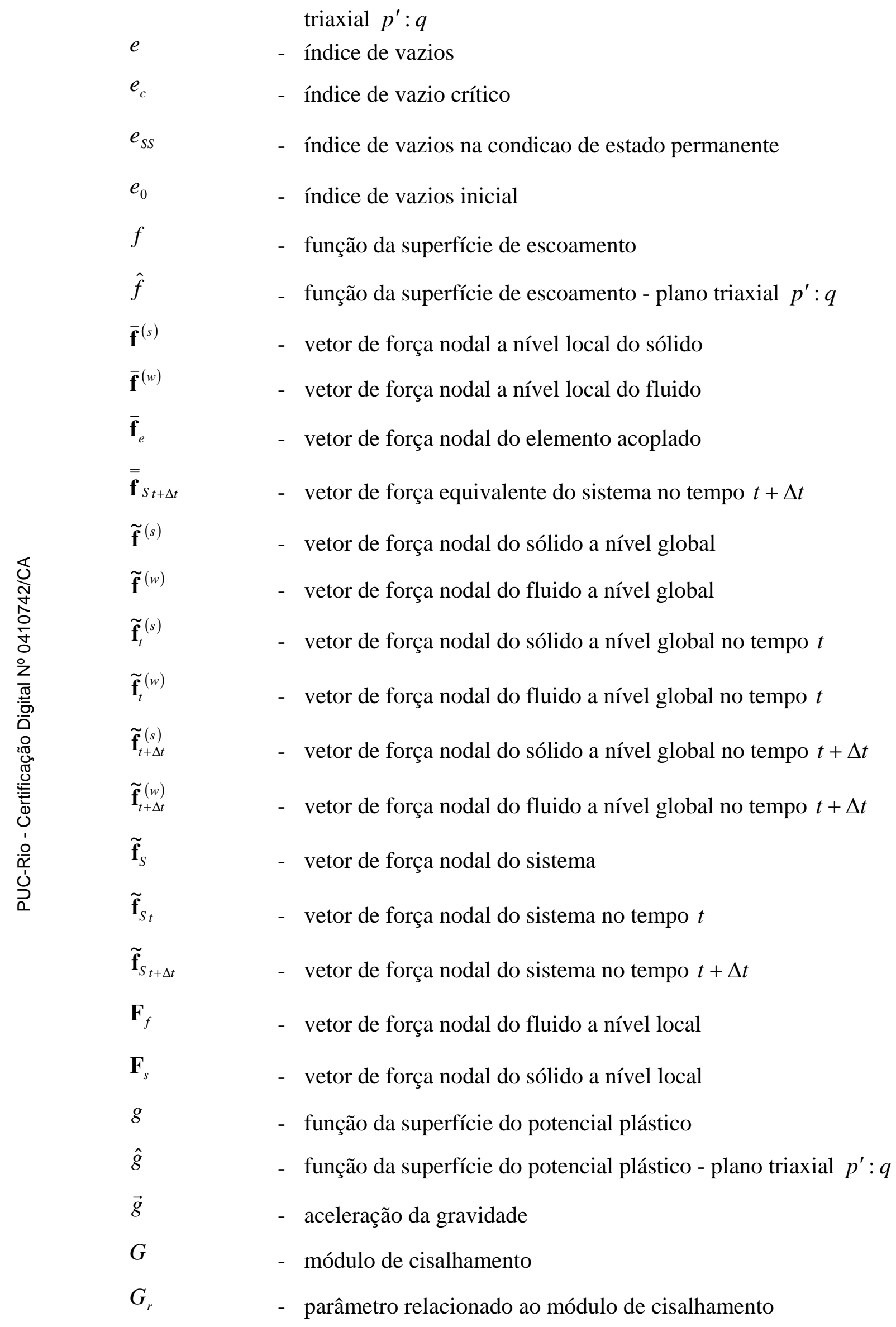




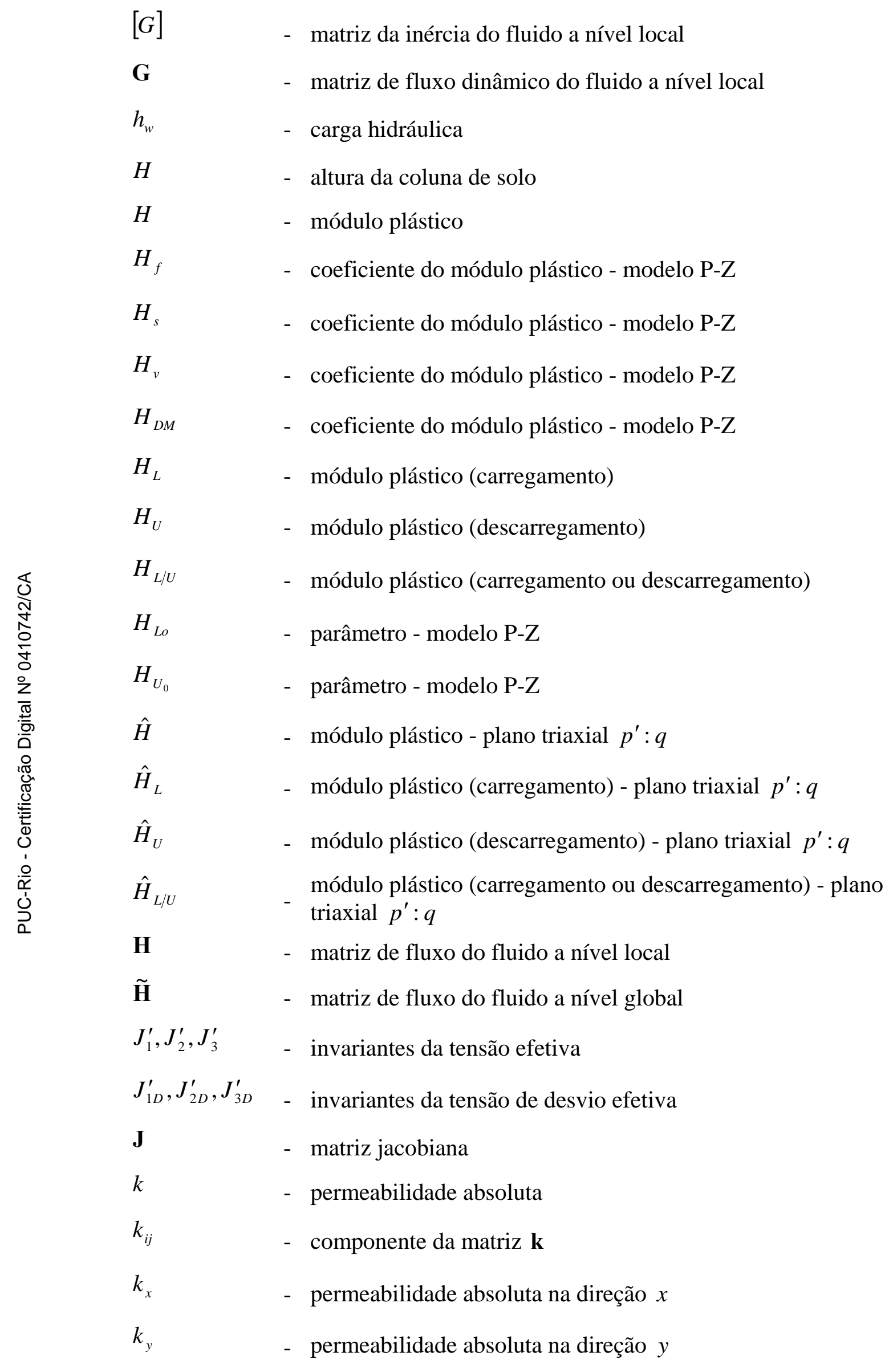




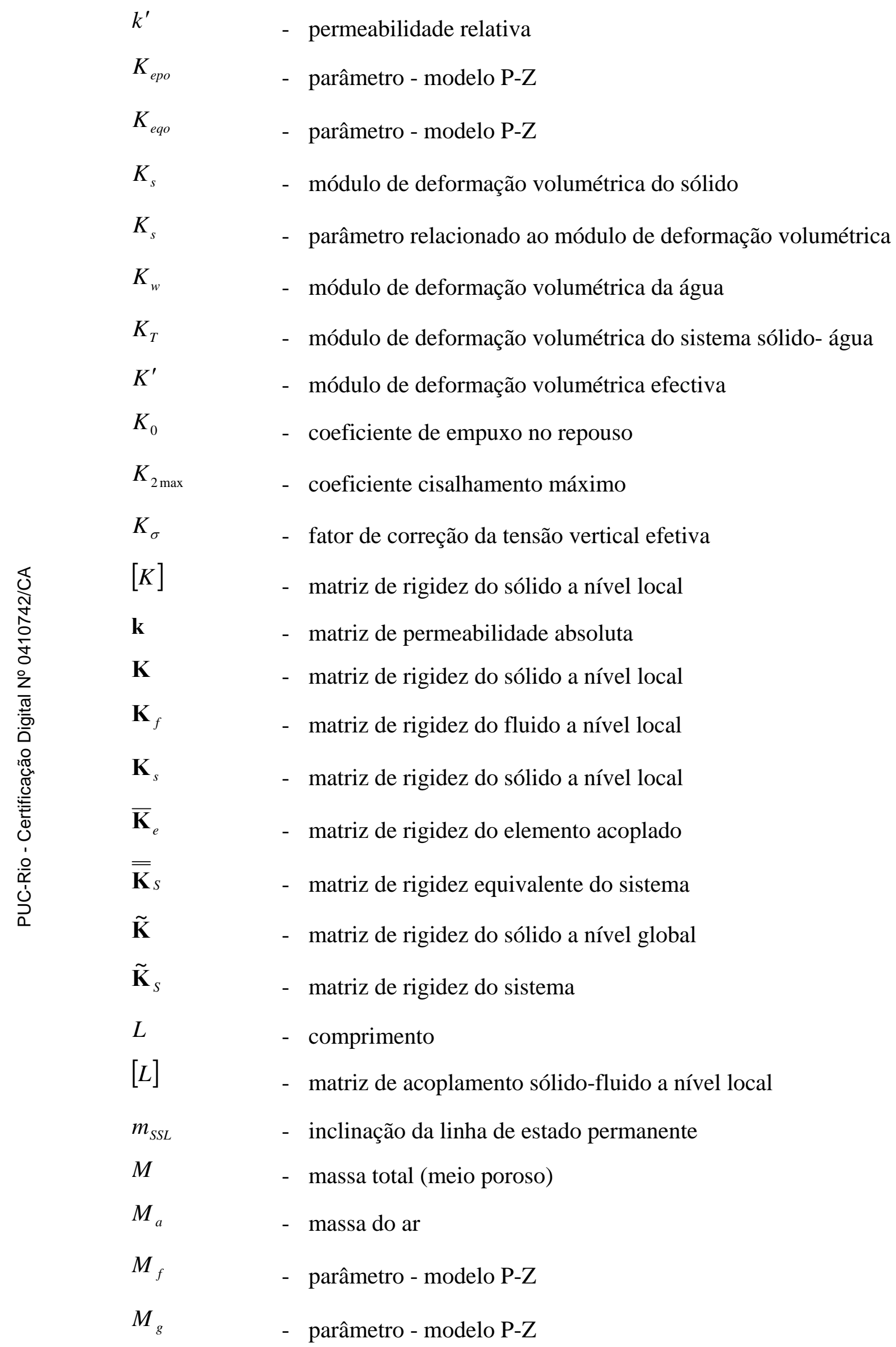




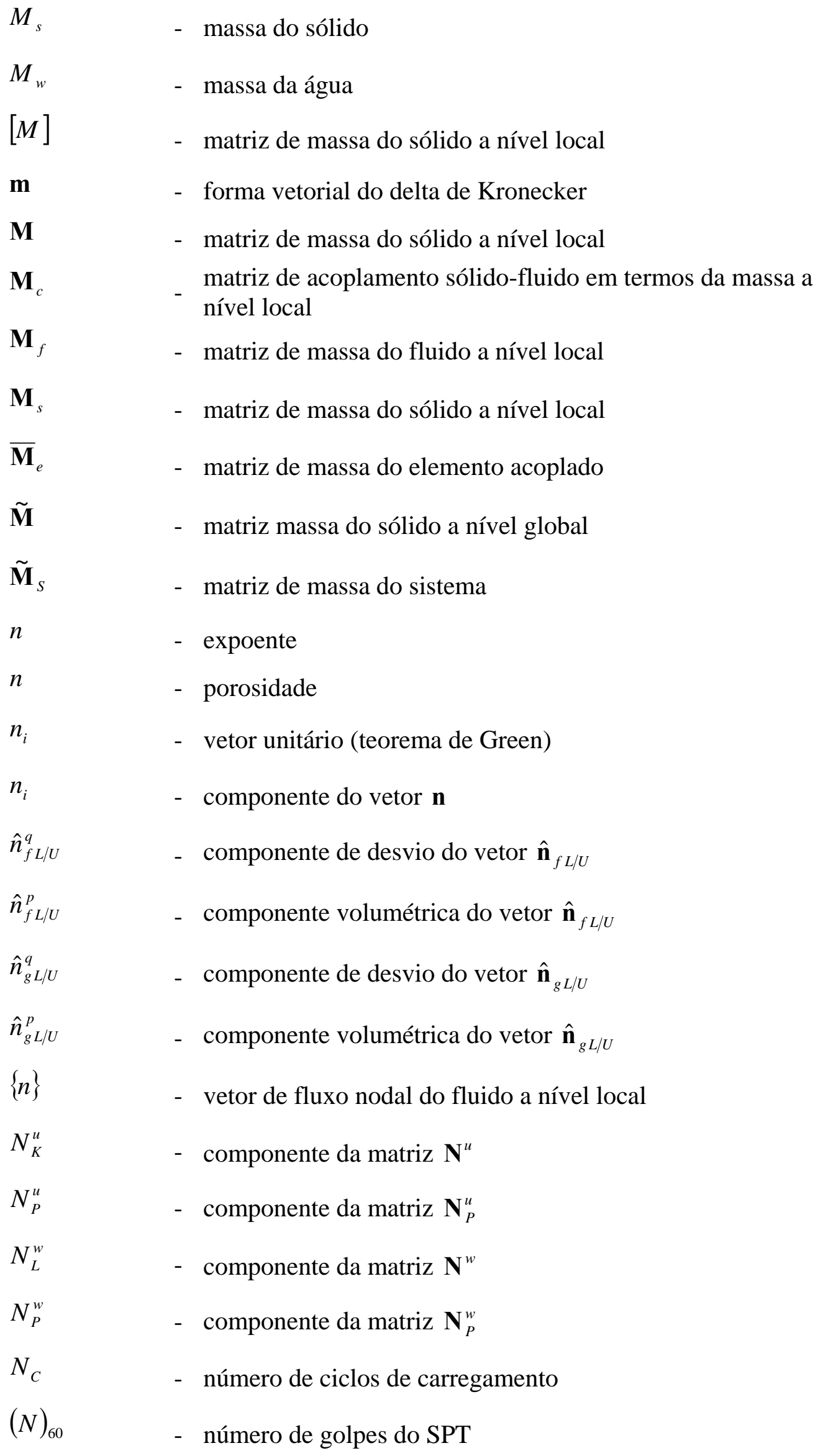




$$
\begin{aligned}
& \left(N_{1}\right)_{60} \quad \text { - número de golpes corrigidos do SPT } \\
& \text { n } \\
& \mathbf{n}_{f_{L}} \\
& \mathbf{n}_{f_{U}} \\
& \mathbf{n}_{f / U} \\
& \mathbf{n}_{g L} \\
& \mathbf{n}_{g U} \\
& \mathbf{n}_{g_{L / U}} \\
& \hat{\mathbf{n}}_{f L / U} \\
& \hat{\mathbf{n}}_{g L / U} \\
& \mathbf{N} \\
& \mathbf{N}^{u} \\
& \mathbf{N}^{w} \\
& \mathbf{N}_{P}^{u} \\
& \mathbf{N}_{P}^{w} \\
& \mathbf{N}_{P} \\
& p_{w} \\
& p_{w i} \\
& \dot{p}_{w} \\
& p^{\prime} \\
& p_{0}^{\prime} \\
& \hat{p}_{f_{0}}^{\prime} \\
& \hat{p}_{g_{0}}^{\prime} \\
& \bar{p}_{w L i} \\
& p_{w i}^{*} \\
& P_{a}
\end{aligned}
$$




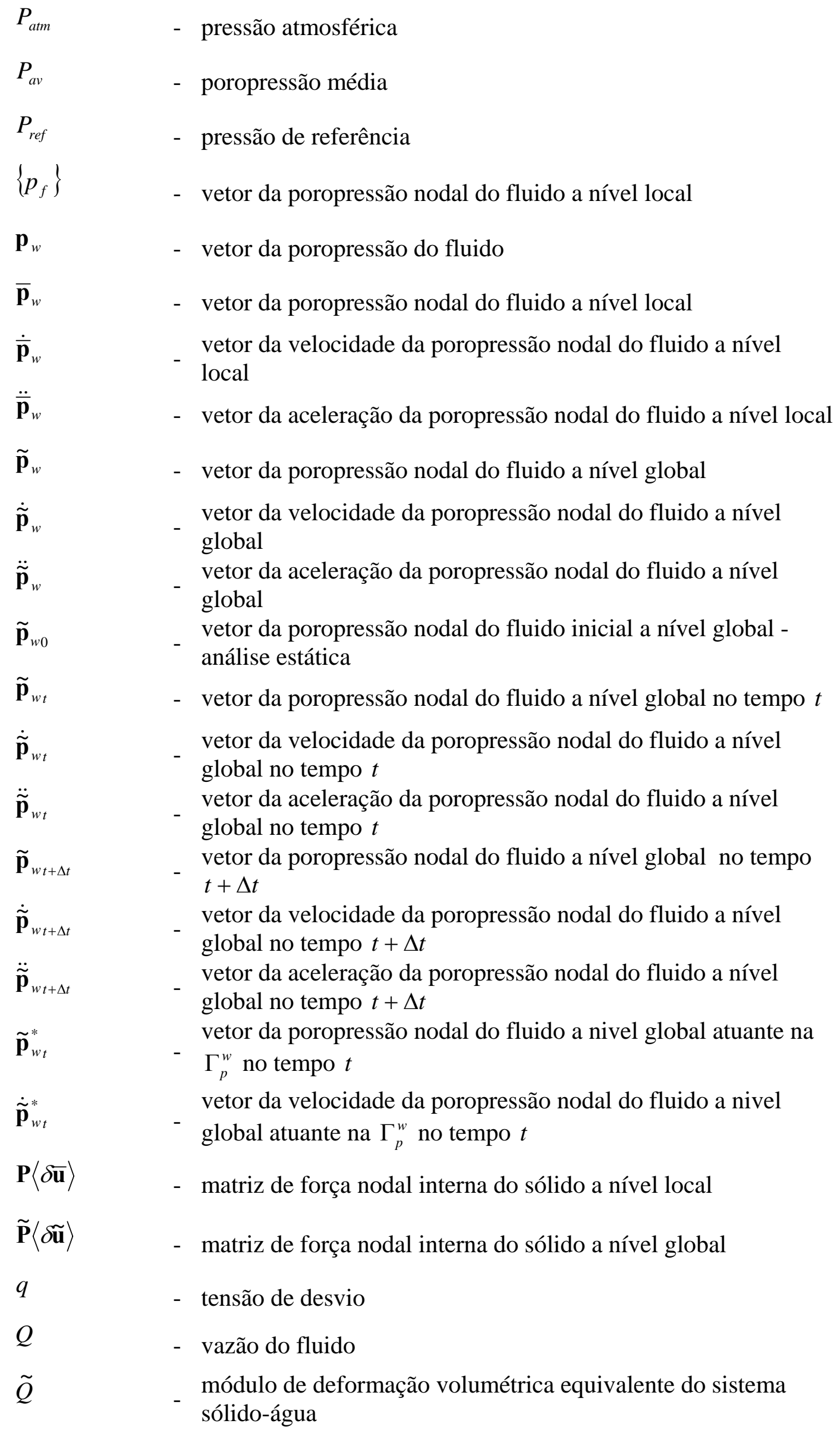

- matriz de força nodal interna do sólido a nível local

- matriz de força nodal interna do sólido a nível global

- tensão de desvio

- vazão do fluido

módulo de deformação volumétrica equivalente do sistema sólido-água 


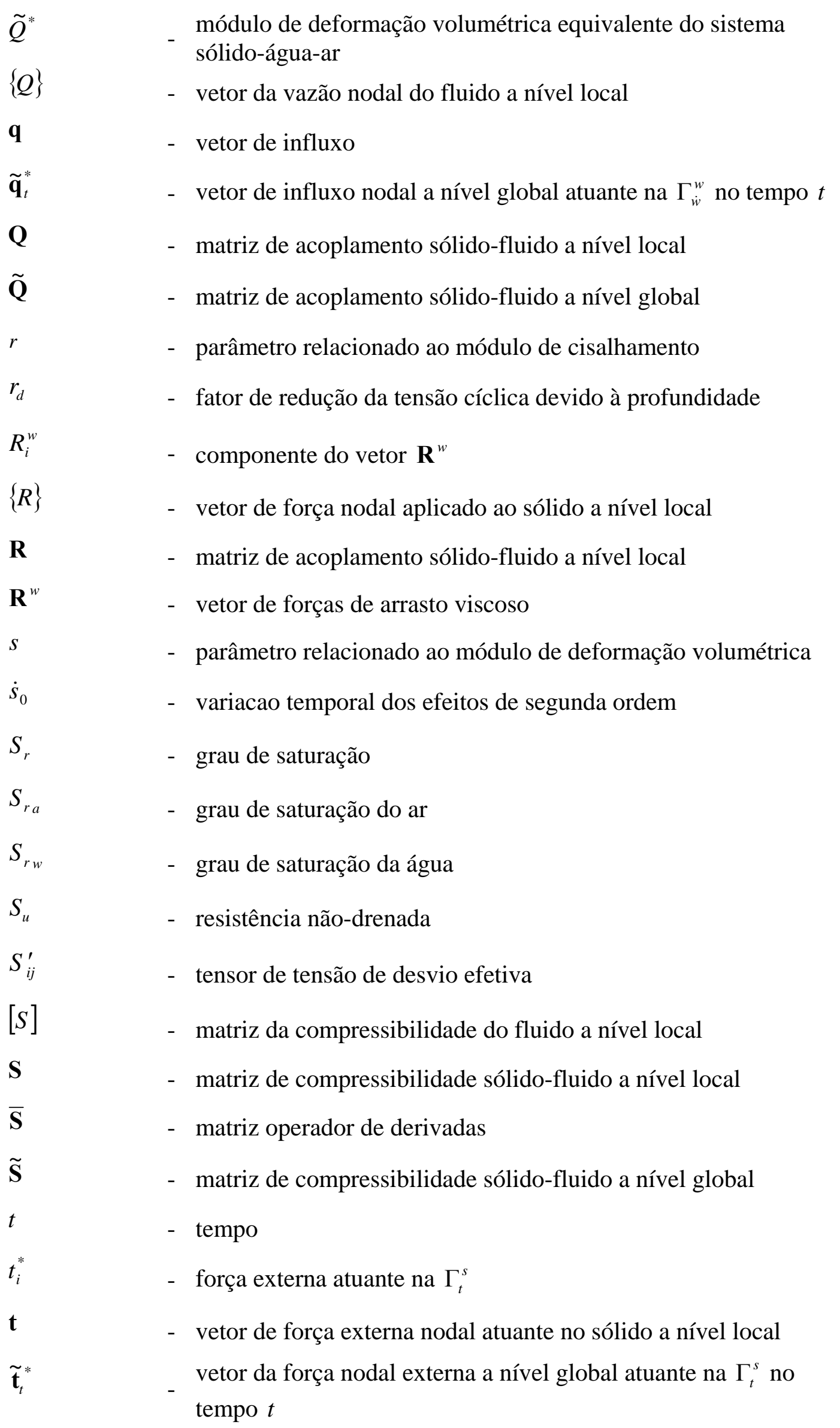


$u_{i}$

$u_{x}$

$u_{i}^{*}$

$\bar{u}_{K i}$

$\{u\}$

$\{\dot{u}\}$

$\{\ddot{u}\}$

$\mathbf{u}$

$\mathbf{u}_{f}$

$\dot{\mathbf{u}}_{f}$

$\ddot{\mathbf{u}}_{f}$

$\mathbf{u}_{s}$

$\dot{\mathbf{u}}_{s}$

$\ddot{\mathbf{u}}_{s}$

$\overline{\mathbf{u}}$

$\dot{\overline{\mathbf{u}}}$

$\ddot{\overline{\mathbf{u}}}$

$\tilde{\mathbf{u}}$

$\dot{\tilde{\mathbf{u}}}$

$\ddot{\tilde{u}}$

$\tilde{\mathbf{u}}_{0}$

$\tilde{\mathbf{u}}_{t}$

$\dot{\tilde{\mathbf{u}}}_{t}$

$\ddot{\tilde{u}}_{t}$

$\tilde{\mathbf{u}}_{t+\Delta t}$

$\dot{\widetilde{\mathbf{u}}}_{t+\Delta t}$
- deslocamento do sólido

- componente do vetor $\mathbf{u}$

- deslocamento horizontal

- deslocamento do sólido prescrito na $\Gamma_{u}^{s}$

- componente do vetor $\overline{\mathbf{u}}$

- vetor de deslocamento nodal do sólido a nível local

- vetor da velocidade nodal do sólido a nível local

- vetor da aceleração nodal do sólido a nível local

- vetor de deslocamento do sólido

- vetor de deslocamento nodal do fluido a nível local

- vetor da velocidade nodal do fluido a nível local

- vetor da aceleração nodal do fluido a nível local

- vetor de deslocamento nodal do sólido a nível local

- vetor da velocidade nodal do sólido a nível local

- vetor da aceleração nodal do sólido a nível local

- vetor de deslocamento nodal do sólido a nível local

- vetor da velocidade nodal do sólido a nível local

- vetor da aceleração nodal do sólido a nível local

- vetor de deslocamento nodal do sólido a nível global

- vetor da velocidade nodal do sólido a nível global

- vetor da aceleração nodal do sólido a nível global vetor da deslocamento nodal do sólido inicial a nível global análise estática vetor da deslocamento nodal do sólido a nível global no tempo $t$

- vetor da velocidade nodal do sólido a nível global no tempo $t$

- vetor da aceleração nodal do sólido a nível global no tempo $t$ vetor da deslocamento nodal do sólido a nível global no tempo $t+\Delta t$ vetor da velocidade nodal do sólido a nível global no tempo $t+\Delta t$ 


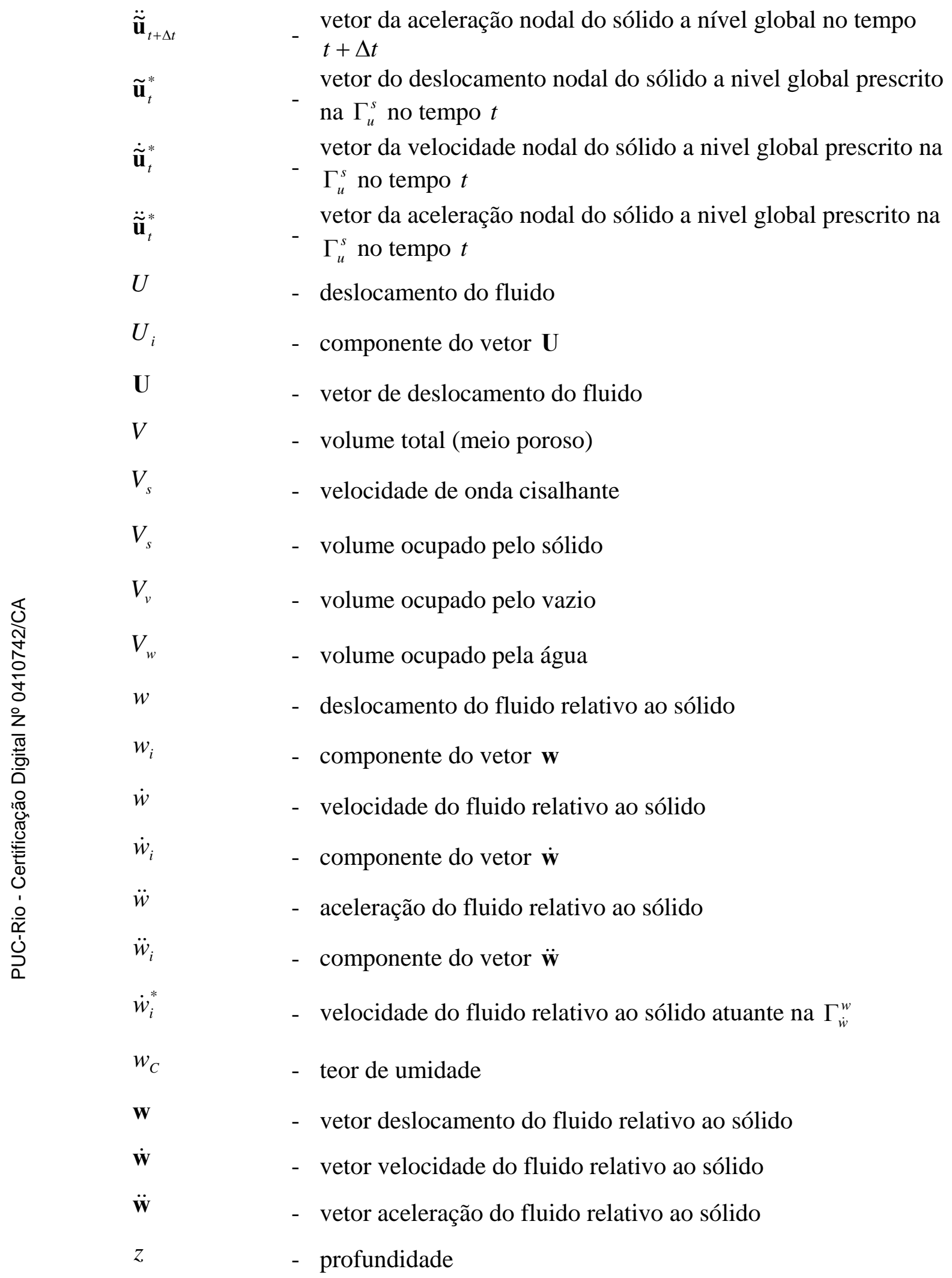




\section{ALFABETO GREGO}

$\alpha$

$\alpha$

$\alpha_{w}$

$\alpha_{r}$

$\alpha_{s}$

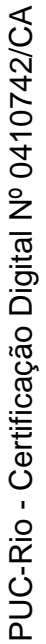

$\alpha_{R}$

$\tilde{\alpha}$

A

$\boldsymbol{\alpha}_{1}, \boldsymbol{\alpha}_{2}, \boldsymbol{\alpha}_{3}$

$\beta$

$\beta_{s}$

$\beta_{\text {s }}$

$\beta_{w}$

$\beta_{R}$

$\beta_{0}$

$\beta_{1}, \beta_{2}$

$\beta_{1}$

$\bar{\beta}_{1}$

$\mathrm{B}_{1}, \mathrm{~B}_{2}$

$\chi$

$\mathrm{X}_{1}, \mathrm{X}_{2}$
- constante do método de Newmark

- parâmetro - modelo P-Z

- constante do método de Newmark para a poropressão do fluido

- parâmetro relacionado ao módulo de cisalhamento constante do método de Newmark para o deslocamento do sólido

- parâmetro do amortecimento de Rayleigh

- constante de Biot

- quantidade escalar

- quantidades vetoriais

- constante do método de Newmark constante do método de Newmark para o deslocamento do sólido

- parâmetro relacionado ao módulo de deformação volumétrica

- constante do método de Newmark para a poropressão do fluido

- parâmetro do amortecimento de Rayleigh

- parâmetro - modelo P-Z

- constantes do método de Newmark Generalizado GN22

- parâmetro - modelo P-Z

- constante do método de Newmark Generalizado GN11

- quantidades escalares

- escalar positivo

- quantidades escalares 


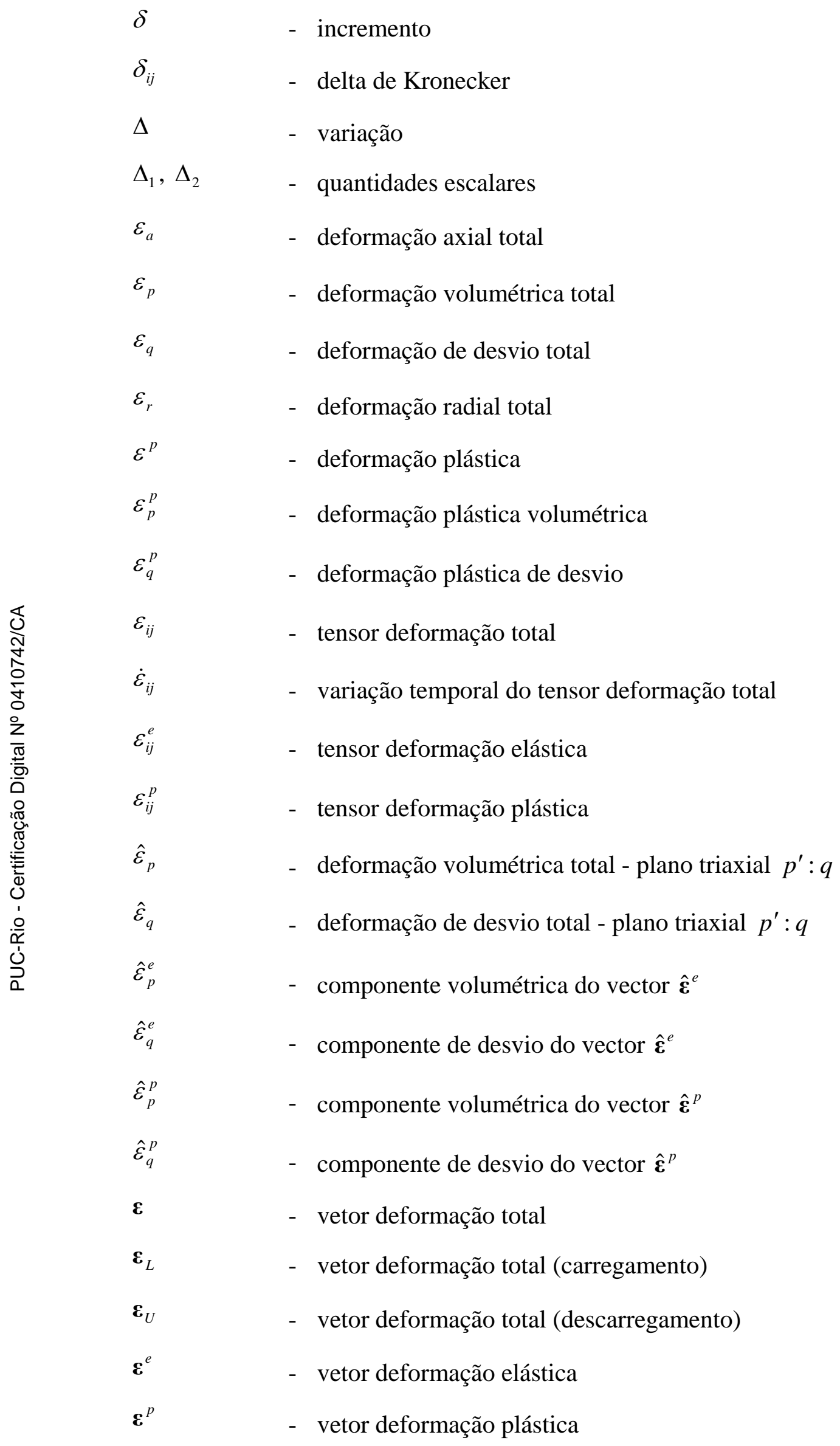


- vetor deformação total - plano triaxial $p^{\prime}: q$

- vetor deformação elástica - plano triaxial $p^{\prime}: q$

- vetor deformação plástica - plano triaxial $p^{\prime}: q$

- ângulo de atrito na condição de estado crítico

- matriz de fluxo nodal do fluido a nível local

- vetor da variável generalizada a nível local

- vetor da velocidade da variável generalizada a nível local

- vetor da aceleração da variável generalizada a nível local

- vetor da variável nodal generalizada a nível local

- vetor da velocidade da variável nodal generalizada a nível local

- vetor da aceleração da variável nodal generalizada a nível local

- vetor da variável nodal generalizada a nível global vetor da velocidade da variável nodal generalizada a nível global vetor da aceleração da variável nodal generalizada a nível global

- vetor da variável nodal generalizada a nível global no tempo $t$ vetor da velocidade da variável nodal generalizada a nível global no tempo $t$ vetor da aceleração da variável nodal generalizada a nível global no tempo $t$ vetor da variável nodal generalizada a nível global no tempo $t+\Delta t$ vetor da velocidade da variável nodal generalizada a nível global no tempo $t+\Delta t$ vetor da aceleração da variável nodal generalizada a nível global no tempo $t+\Delta t$ vetor da variável nodal generalizada a nível global na condição inicial

- parâmetro - modelo P-Z

- parâmetro - modelo P-Z

- contorno

- condição de contorno do sólido

- condição de contorno do fluido

- condição de contorno do sólido em termos de força 


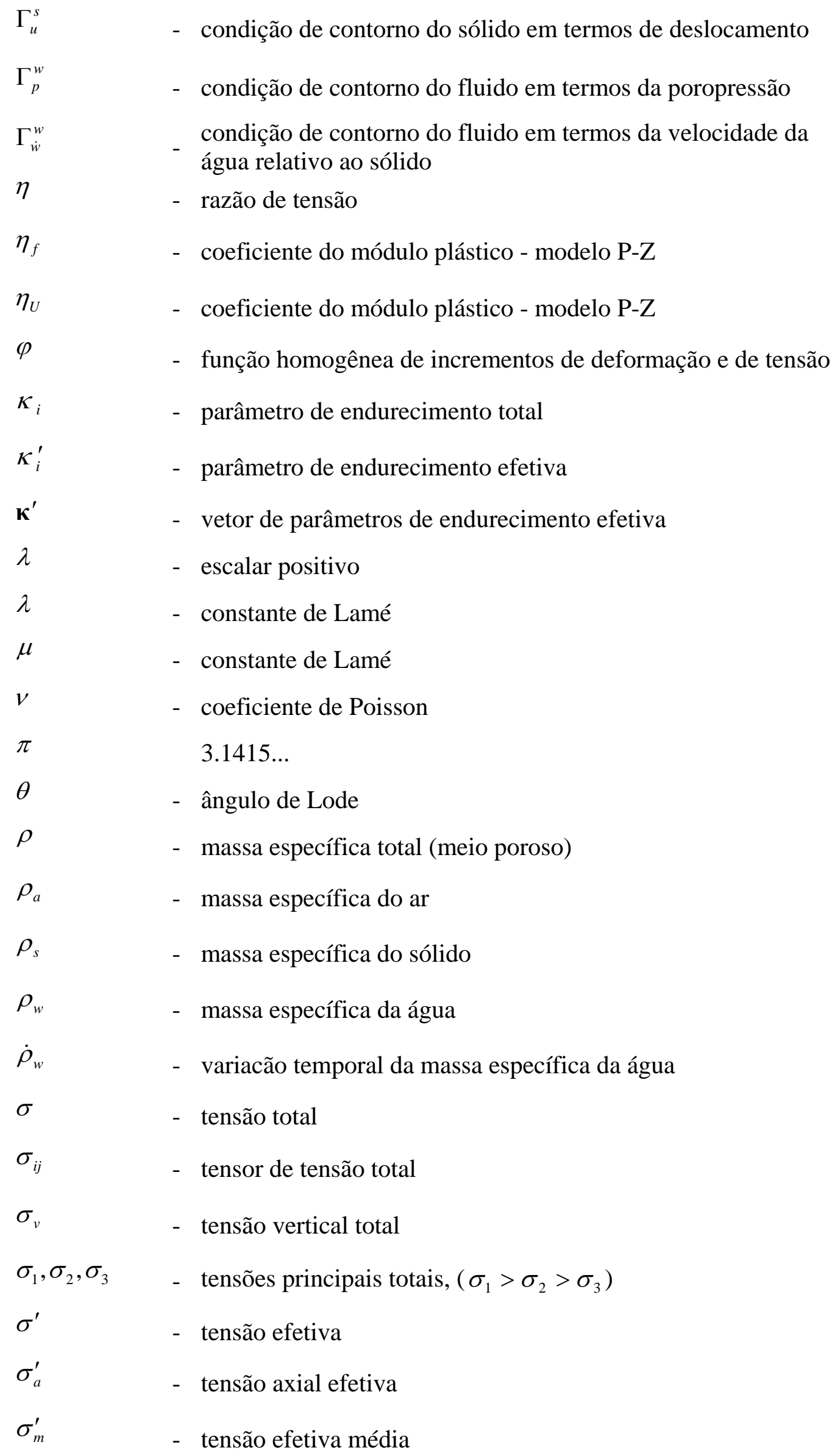




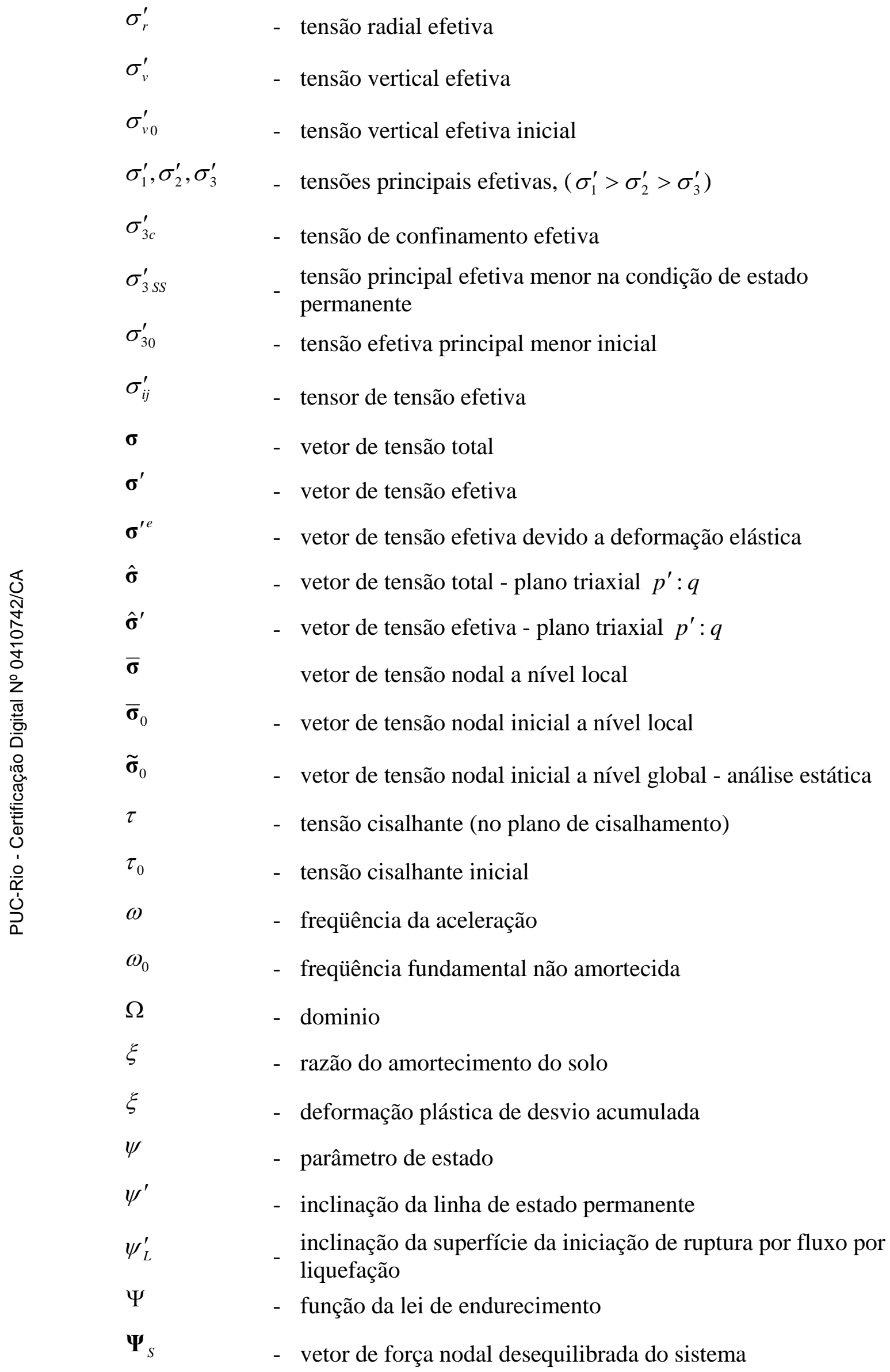


$\boldsymbol{\Psi}^{(s)}$

$\boldsymbol{\Psi}^{(w)}$

$\zeta$

vetor de força nodal desequilibrada devido ao sólido a nível global

vetor de força nodal desequilibrada devido ao fluido a nível global

- coeficiente do módulo plástico - modelo P-Z 
Paciencia y buen humor.

Don Max.

Há homens que lutam um dia e são bons, há outros que lutam um ano e são melhores, há os que lutam muitos anos e são muito bons, mas há os que lutam toda a vida e estes são imprescindíveis.

Bertold Brecht. 